\title{
[18F]-T807 tauopathy PET imaging in chronic traumatic
}

\section{encephalopathy [version 1; peer review: 2 approved]}

\author{
Sam Gandy (iD), Steven T. DeKosky² \\ ${ }^{1}$ Icahn School of Medicine at Mount Sinai, New York, NY, 10029, USA \\ 2University of Virginia School of Medicine, Charlottesville, VA, 22908, USA
}

\author{
V1 First published: $29 \operatorname{Sep} 2014, \mathbf{3 : 2 2 9}$ \\ https://doi.org/10.12688/f1000research.5372.1 \\ Latest published: 29 Sep 2014, 3:229 \\ https://doi.org/10.12688/f1000research.5372.1
}

\section{Abstract}

A new molecular ligand for positron emission tomography (PET) of the human brain, [18F]-T807, is under investigation for the antemortem detection of pathological neurofibrillary aggregates, which are evidence of neurofibrillary tangle (NFT) diseases, also known as tauopathies. Repetitive mild traumatic brain injuries in athletes and battlefield veterans are associated with one such tauopathy, known as chronic traumatic encephalopathy (CTE). In a recent case report, a former NFL player with clinically probable CTE and a concurrent Progressive Supranuclear Palsy (PSP) -like syndrome was studied using [18F]-T807. The interpretation of this player's [18F]-T807 PET imaging was complicated by the overlap of tracer uptake in brain regions involved in CTE and PSP with regions associated with either nonspecific [18F]-T807 ligand binding or "aging-associated" binding of [18F]-T807 to authentic tauopathy known to be associated with aging and disease severity (i.e., NFT in the mesial temporal lobe). The implications of these data for the utility of [18F]-T807 in the premortem detection of CTE are summarized.

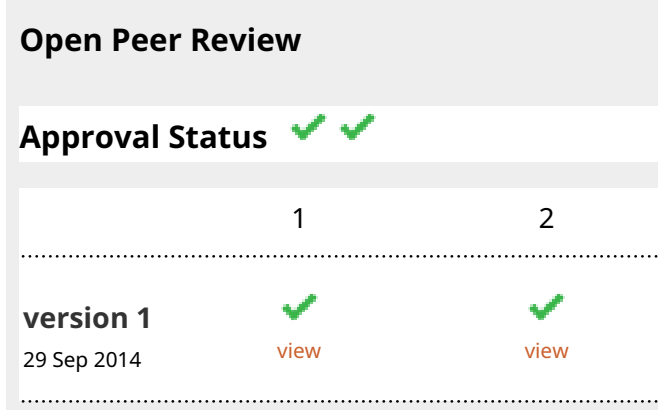

1. Victor Villemagne, University of Melbourne, Parkville, Australia

2. Nobuyuki Okamura, Tohoku University, Sendai, Japan

Any reports and responses or comments on the article can be found at the end of the article.

Corresponding author: Sam Gandy (samuel.gandy@mssm.edu)

Competing interests: No competing interests were disclosed.

Grant information: The author(s) declared that no grants were involved in supporting this work.

Copyright: (c) 2014 Gandy S and DeKosky ST. This is an open access article distributed under the terms of the Creative Commons Attribution License, which permits unrestricted use, distribution, and reproduction in any medium, provided the original work is properly cited. Data associated with the article are available under the terms of the Creative Commons Zero "No rights reserved" data waiver (CCO 1.0 Public domain dedication).

How to cite this article: Gandy S and DeKosky ST. [18F]-T807 tauopathy PET imaging in chronic traumatic encephalopathy [version 1; peer review: 2 approved] F1000Research 2014, 3:229 https://doi.org/10.12688/f1000research.5372.1

First published: 29 Sep 2014, 3:229 https://doi.org/10.12688/f1000research.5372.1 


\section{Correspondence}

We recently reported the case of a retired NFL player with a clinical diagnosis of chronic traumatic encephalopathy (CTE); the diagnosis was based on clinical characteristics of his progressive cognitive disorder and negative [18F]-florbetapir PET brain imaging indicating absence of amyloid plaques in his brain (Mitsis et al. 2014) ${ }^{1}$. An [18F]-T807 PET imaging study revealed retention of [18F]-T807 in the substantia nigra (SN), globus pallidi (GP), and hippocampi, bilaterally. Key images from that paper were reproduced in a recent review by Gandy et al. $(2014)^{2}$. The pattern of retention was interpreted by the original authors as potentially consistent with the clinical diagnosis of $\mathrm{CTE}^{1}$.

The anatomical distribution of [18F]-T807 retention was interpreted as atypical and suggestive of the distribution of pathology in Progressive Supranuclear Palsy (PSP). That interpretation was noted in the Mitsis et al. (2014) paper $^{1}$ in light of a recent case report linking CTE and $\mathrm{PSP}^{3}$ and because the subject in the Mitsis et al. (2014) ${ }^{1}$ case manifested nasal speech, hypomimia, and impaired upgaze, all features of PSP. These facts notwithstanding, we emphasize that we cannot exclude the possibility that the pattern of [18F]-T807 binding observed in the retired NFL player could be the result of nonspecific retention of [18F]-T807 in these same regions of brain. Indeed, some as-yet unpublished experience with $[18 \mathrm{~F}]-\mathrm{T} 807$ has demonstrated a propensity of the ligand to bind to the SN and GP in what appears to be a non-specific fashion (http:// www.alzforum.org/news/conference-coverage/tau-tracers-shineboston-conference). The [18F]-T807 binding to the hippocampi in $^{1}$ could fall within the spectrum of aging-related tauopathy, the known deposition of NFT in this region (http://www.alzforum.org/ news/conference-coverage/tau-tracers-shine-bostonconference). We write here to emphasize the point that proof of the histological underpinnings of $[18 \mathrm{~F}]-\mathrm{T} 807$ binding awaits the presentation of a sufficiently powered study of in vivo-radiological/postmortemhistological correlation relationships, and as a reminder that while the development of several putative tau-binding ligands has opened new possibilities for research and clinical use, that none have been validated to the extent necessary for reliable use and such validation should be a top priority.

\section{Author contributions}

This manuscript was drafted by S.G. and edited by S.T. DeK.

\section{Competing interests}

No competing interests were disclosed.

Grant information

The author(s) declared that no grants were involved in supporting this work.
1. Mitsis EM, Riggio S, Kostakoglu L, et al.: Tauopathy PET and amyloid PET in the diagnosis of chronic traumatic encephalopathies: studies of a retired NFL player and of a man with FTD and a severe head injury. Transl Psychiatry. 2014; 4: e441. PubMed Abstract | Publisher Full Text

2. Gandy S, Ikonomovic MD, Mitsis E, et al.: Chronic traumatic encephalopathy: clinical-biomarker correlations and current concepts in pathogenesis. $\mathrm{Mol}$
Neurodegener. 2014; 9(1): 37 PubMed Abstract | Publisher Full Text

3. Ling H, Kara E, Revesz T, et al.: Concomitant progressive supranuclear palsy and chronic traumatic encephalopathy in a boxer. Acta Neuropathol Commun. 2014; 2: 24.

PubMed Abstract | Publisher Full Text | Free Full Text 


\section{Open Peer Review}

\section{Current Peer Review Status:}

\section{Version 1}

Reviewer Report 20 November 2014

https://doi.org/10.5256/f1000research.5735.r6684

(C) 2014 Okamura N. This is an open access peer review report distributed under the terms of the Creative Commons Attribution License, which permits unrestricted use, distribution, and reproduction in any medium, provided the original work is properly cited.

\section{Nobuyuki Okamura}

Department of Pharmacology, Tohoku University, Sendai, Japan

In this letter, the authors describe an alternative explanation of $\left[{ }^{18} \mathrm{~F}\right]$ T807 PET findings in patients with chronic traumatic encephalopathy (CTE). A striking article by Mitsis et al. (2014) has suggested the potential usefulness of tau PET imaging for the early detection of tau deposits in patients with CTE. The authors of the letter state that tracer signals in the substantia nigra and globus pallidus might be the result of nonspecific retention of [ $\left.{ }^{18} \mathrm{~F}\right] \mathrm{T} 807$. However, the amount of hippocampal $\left[^{18}\right.$ F]T807 retention (SUVR 1.45) was considerably higher than the values that have been previously reported in healthy controls, suggesting the involvement of the hippocampus in this patient. It is important to confirm whether the hippocampal $\left[{ }^{18} \mathrm{~F}\right]$ T807 retention was within normal ageappropriate levels or whether it reflected CTE tau lesions in this case. Furthermore, the current findings should be confirmed by postmortem examinations in the future.

Competing Interests: No competing interests were disclosed.

I confirm that I have read this submission and believe that I have an appropriate level of expertise to confirm that it is of an acceptable scientific standard.

Reviewer Report 06 October 2014

https://doi.org/10.5256/f1000research.5735.r6252

(C) 2014 Villemagne V. This is an open access peer review report distributed under the terms of the Creative Commons Attribution License, which permits unrestricted use, distribution, and reproduction in any medium, provided the original work is properly cited.

\section{Victor Villemagne}

The Florey Institute of Neuroscience and Mental Health, University of Melbourne, Parkville, VIC, Australia 
This timely letter by Drs Gandy and DeKosky sheds light onto the inherent difficulties of using not yet fully characterized imaging markers where lack of validation of the tracers used, coupled with limited experience in an emergent field, might potentially lead to over- or under-interpretation of the results, especially when no controls are available to juxtapose the findings. This in turn might reflect badly on the value of this new approach. Larger cohort studies and, as the authors point out, neuropathological confirmation of the imaging findings will be required to fully validate and characterize the binding of these new and essential markers for the in vivo imaging of tau deposits in the brain.

Competing Interests: No competing interests were disclosed.

\section{I confirm that I have read this submission and believe that I have an appropriate level of} expertise to confirm that it is of an acceptable scientific standard.

The benefits of publishing with F1000Research:

- Your article is published within days, with no editorial bias

- You can publish traditional articles, null/negative results, case reports, data notes and more

- The peer review process is transparent and collaborative

- Your article is indexed in PubMed after passing peer review

- Dedicated customer support at every stage

For pre-submission enquiries, contact research@f1000.com 